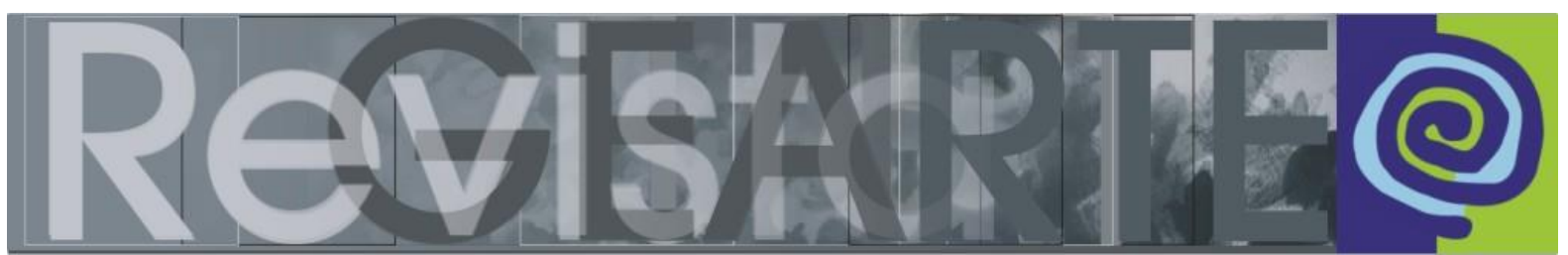

ISSN 2357-9854 | e-ISSN 2596-3198 (online)

\title{
De linhas e marcas de existência: o evento pedagógico como evento artístico
}

\author{
Tatiana Fernández \\ (Universidade de Brasília — UnB, Brasília/DF, Brasil)
}

\begin{abstract}
RESUMO - De linhas e marcas de existência: o evento pedagógico como evento artístico Este artigo apresenta reflexões provenientes dos Estágios Supervisionados em Artes Visuais na Universidade de Brasília sobre a aula como uma marca na construção de uma vida. Com base nas ideias da pedagogia do evento e imanência da aprendizagem de Denis Atkinson e da metodologia de Investigação Baseada em Arte (IBA), a autora analisa linhas de fuga à rigidez dos modelos educativos transcendentalistas com cinco aberturas nos processos de aprendizagem: à imaginação, subjetivação, corporificação, singularização e diferenciação. Com isto, aponta para a relevância de criar eventos pedagógicos como eventos artísticos que considerem as linhas de aprendizagem dos estudantes.
\end{abstract}

PALAVRAS-CHAVE:

Pedagogia do evento. Imanência da aprendizagem. Investigação Baseada em Arte. Linhas de aprendizagem.

ABSTRACT - About lines and marks of existence: the pedagogical event as an artistic event - This article presents reflections from University of Brasilia's discipline of visual art education internship about classroom as a mark in the process of building a life. Based on the idea of pedagogy of the event and the immanence of learning of Dennis Atkinson and Art Based Research (ABR), methodology, the author analyses lines of scape from the rigid transcendentalist education models with five openings on learning processes: to imagination, subjectivation, corporification, singularization and differentiation. Along with it, she points out to the relevance of creating pedagogical events as artistic events that considers the students lines of learning.

KEYWORDS:

Pedagogy of the event. Immanence of learning. Arts Based Research. Lines of learning.

RESUMEN - De líneas y marcas de existencia: el evento pedagógico como evento artístico - Este artículo presenta reflexiones provenientes de las pasantías en educación artística de la Universidad de Brasilia sobre el aula como una marca en la construcción de una vida. A partir de las ideas de pedagogía del evento y la inmanencia del aprendizaje de Dennis Atkinson y la metodología de Investigación Basada en Arte (IBA), la autora analiza líneas de fuga a la rigidez de los modelos educativos trascendentalistas con cinco aperturas en los procesos de aprendizaje: a la imaginación, subjetivación, corporificación, singularización y diferenciación. Con esto, señala la relevancia de crear eventos pedagógicos como eventos artísticos que consideren las líneas de aprendizaje de los estudiantes.

PALABRAS CLAVE:

Pedagogía del evento. Inmanencia del aprendizaje. Investigación Basada en Arte. Líneas de aprendizaje. 


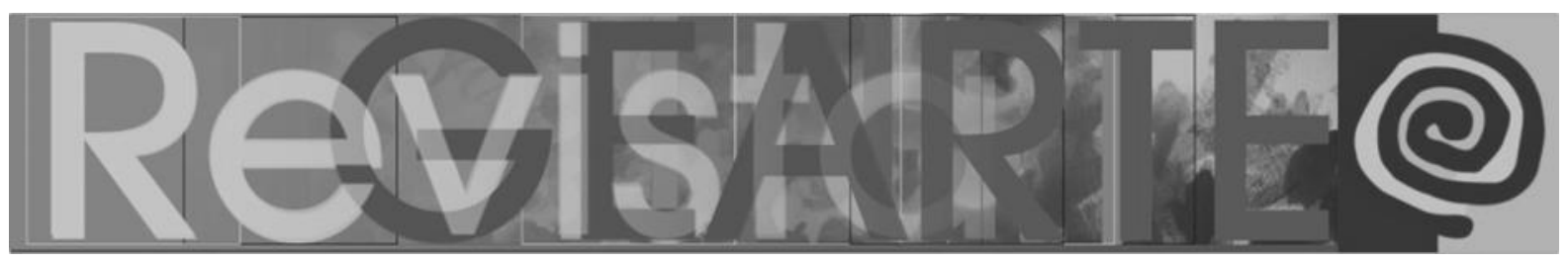

\section{A marca da existência: uma linha pedagógica}

A primeira coisa a fazer em um processo criativo é fazer uma marca. É um momento abstrato quando, de uma hora para a outra, passa-se da não existência à existência. A marca pode ser uma linha, uma palavra, um som, um movimento ou algo que marque o estado de existência do pensamento. $O$ ato de criação é, portanto, um salto no desconhecido ou inexistente. A palavra criar é dos romanos e, na Idade Média, a cristandade usou exclusivamente para a ideia de criar do nada: Creatio Ex-nihilo, dada como uma faculdade divina. Já fabricar ou produzir, diferentemente de criar, referem-se a uma elaboração a partir do existente. Na era moderna, a capacidade criativa se atribui aos artistas e no século XX cresce 0 entendimento de que é uma capacidade humana. Dentro de tudo, a discussão do poder criativo, sendo um poder, entra na discussão política. Na segunda década do século XXI já se fala de uma 'economia criativa'. A criatividade é considerada, hoje, um diferencial econômico e cultural que interessa às sociedades contemporâneas.

Na prática das artes visuais, a criação pode começar por uma linha, uma mancha, um enquadre, uma ação; seja intencional ou casual, direta ou indiretamente. Com uma marca, passa-se do nada ao algo. Quando acontece o primeiro traço, a primeira imagem, a primeira marca de existência, o espaço vazio se torna cheio. E esse instante é, antes de tudo, uma marca em grau zero de significância. É um ato pleno de territorialização, de presença e de poder na construção de uma vida. Da mesma forma que são as garatujas das crianças nos primeiros anos de vida ou as marcas que deixamos sobre a Terra como humanos. Nesse caso, criar é marcar a presença, a existência.

Nessas linhas, podemos nos perguntar: como pensar a aula como uma marca na construção de uma vida? Como pensar a aula como um ato de criação? Ou, como uma marca que inicia um processo de aprendizagem de todos os participantes? Essas perguntas me acompanharam de forma insistente nos anos que trabalhei no ensino de artes visuais, no qual essas perguntas são ainda mais 


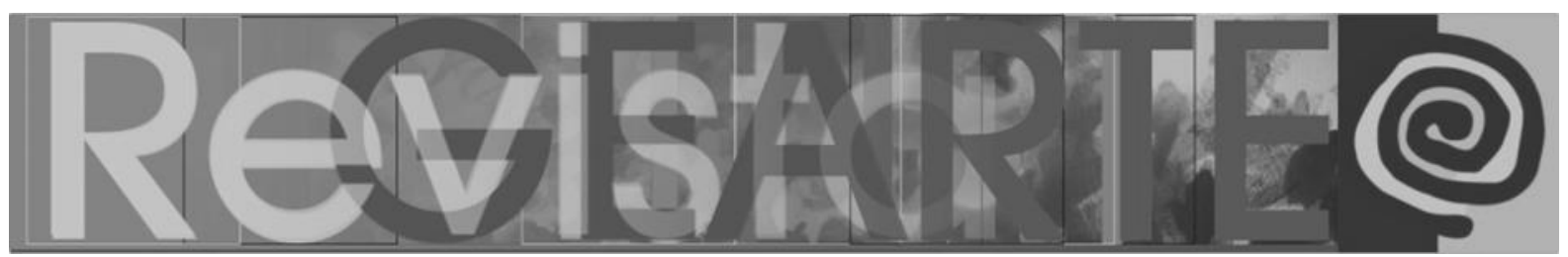

relevantes. Pensando nisso, comecei pintando uma linha branca no meio do meu rosto quando dava aula no ensino básico, há duas décadas. É uma ação que inscreve o tempo e espaço em grau zero de significância e, ao mesmo tempo, de plena existência. $O$ que há atrás dessa linha que alguns decifram como ritual religioso ou símbolo indígena de pintura corporal? Para mim, pintar a linha para dividir o rosto se torna uma preparação para entrar em cena e marcar o espaço de ação. Marca a minha transformação de um estado a outro, como acontece com a obra de arte quando entra na galeria e, assim, nesse momento, declaro-me participante de um evento artístico como pedagogia. A linha marca um evento, no sentido que dá o teórico da educação em artes visuais, Dennis Atkinson (2018), ao que ele chama de pedagogia do evento. A linha abre um espaço estético para ser construído, abre-se ao desconhecido da aprendizagem.

O desconhecido no âmbito escolar é tabu. Tudo aquilo que perturba a ordem do programado, padronizado ou normatizado é criticado e evitado. Das minhas lembranças de professora de arte em escolas particulares, destaca-se a de um diretor que criticava a sujeira do material recortado na sala de aula de arte do primeiro ano do ensino básico. Lembro também de uma diretora que proibia o trabalho com argila ou fotografia com os estudantes na aula de arte, para evitar atos de indisciplina. E a mais anedótica é a do agente de disciplina que chamava a atenção dos estudantes que jogavam futebol e fotografavam como performance artística na hora da aula de arte, pois ele não acreditava nos argumentos dos estudantes de que aquilo era arte. Foi extraordinário como os estudantes defenderam a visão contemporânea da arte por amarem o futebol e por acreditarem, muito convenientemente, que isso poderia ser arte a partir das discussões que tivemos em aula. É possível pensar que há aprendizagem quando os eventos afetam outros participantes, além dos estudantes.

Meu caminho artístico-pedagógico começou com uma linha no rosto de professora de ensino básico e continua hoje na formação de professores de arte. Essa linha marca um antes e um depois, uma desterritorialização da minha relação com a arte e comigo mesma. O percurso que essa linha marca é desordenado e 


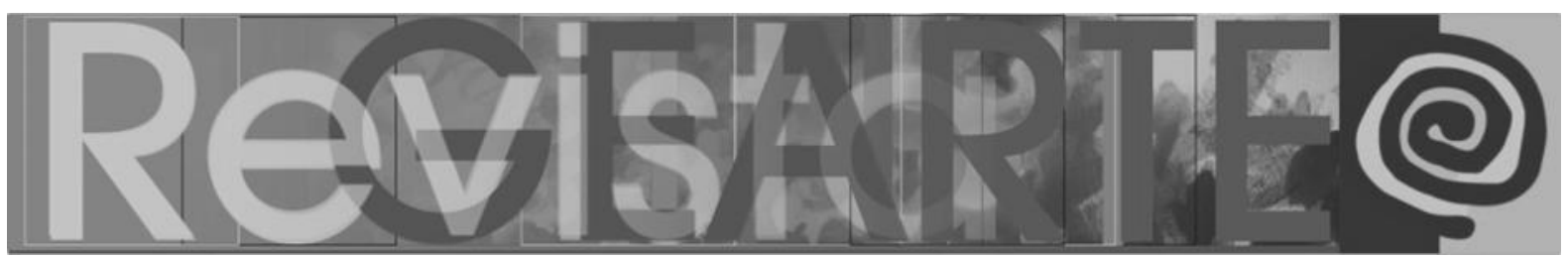

opera em diversos registros como o pedagógico, laboral, acadêmico ou artístico. Como descreve Graeme Sullivan (2010), na sua pesquisa sobre os processos artísticos como investigação, os processos criativos são imprevisíveis e tão diversos como cada situação. Ele lembra que a pesquisa na ciência é um caminho reto entre a indagação e o resultado, pois é necessário saber onde se quer chegar, por isso se parte de uma hipótese. Essa linha reta é apreciada nos processos de aprendizagem na escola tradicional. Por outra parte, também observa que, na área das humanidades, os percursos de pesquisa se dão não em linha reta, mas em círculos ao redor dos diferentes aspectos que afetam uma situação. Diferente dessas formas de percorrer os caminhos de pesquisa, a prática artística abre caminhos exploratórios que podem ir em qualquer direção determinados pelos eventos que a atravessam. Os caminhos da arte não são lineares nem circulares, são caminhos desordenados que se abrem ao aqui e agora e se conectam a outros caminhos.

Esta forma de pesquisa é a chamada Investigação Baseada em Arte ou IBA (BARONE e EISNER, 2012; DIAS, 2016). O uso de IBA não constitui em si mesma uma metodologia para criar obras de arte, mas para criar conhecimento com as formas de operar das artes. São formas de operar que se manifestam de forma sensível e significativa com desdobramentos complexos e profundos. Essas formas de investigação têm qualidades potencialmente pedagógicas. A IBA constitui, assim, uma forma de ensinar, porque articula o ser e o mundo, o eu e o outro, o corpo e a mente. Isso inclui o desenvolvimento de competências, habilidades, destrezas e atitudes que se requerem no fortalecimento cognitivo e emocional e ainda é flexível o suficiente para que as diversas inteligências (GARDNER, 2011) sejam nutridas. Mas, sobretudo, potencializa a capacidade criativa.

A linha no rosto constitui uma forma rudimentar e primária de IBA e de Investigação Educacional Baseada em Artes (IEBA) porque propiciou um caminho de investigação e de relação com outras formas de intervenção estética. Além do mais, a linha me permitiu estabelecer uma conversação com meus estudantes e com o currículo. Ao tempo em que é uma marca de minha condição artística e pedagogicamente desobediente, aponta sobre o corpo como espaço de luta e 


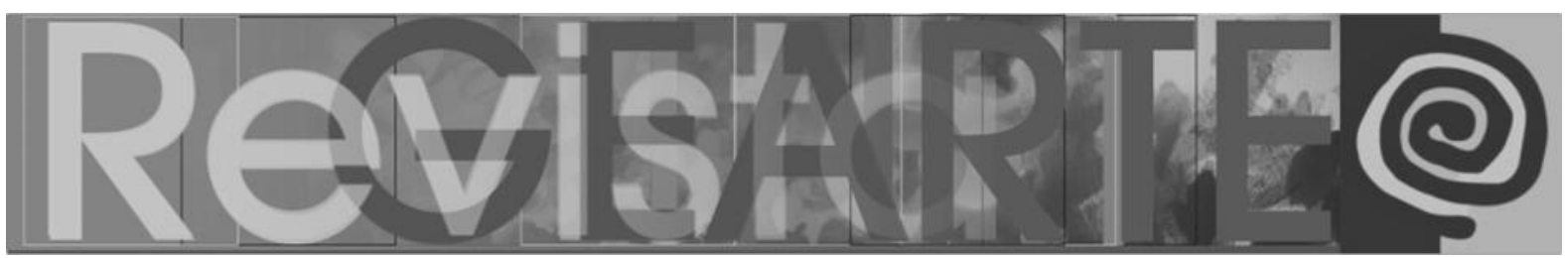

emancipação da normatização e homogeneização que se procura em uma instituição educativa e ao mesmo tempo do policiamento das instituições artísticas (WRIGHT, 2006, 2008). É uma linha de fuga. Essa linha de fuga marcou minha cumplicidade com o espirito irreverente da juventude e alegre das crianças. Finalmente, a linha foi e é ainda importante na minha relação com os estudantes porque nós, professores, afetamos com nossas ações muito mais do que com palavras ou conteúdo.

\section{O evento e as linhas de aprendizagem}

Comparto, com a artista boliviana Narda Alvarado (FERNÁNDEZ, 2015), a inquietação por encontrar formas de comunicação com os estudantes na escola que sejam estabelecidas no plano artístico-poético. Primeiro, é necessário se encontrar com os estudantes na experiência da arte. É necessário estar no evento artístico, não no sentido de visitante de galeria ou museu, mas no sentido do participante que é tomado pelos eventos da arte atravessando seu espaço escolar ordenado. É esse o sentido de 'evento' que Atkinson (2018) usa do filósofo Alain Badiu (2005): algo que sucede, que nos tira do espaço conhecido e nos lança ao desconhecido. Algo que nos afeta, mas que ainda não tem um nome. Sabemos quando um evento nos atravessa, mas não sabemos o que vai resultar desse movimento. O evento nos obriga repensar, mudar e, muitas vezes, a criar novas estruturas para nomear o que antes não existia.

Em segundo lugar, é recomendável prestar atenção às formas em que aprendem os nossos estudantes. Mas pode tomar um tempo enquanto construímos pontes. Esse tempo é radicalmente importante. Para que o evento da arte provoque indagações e posteriores aprendizagens deveremos, como professores de arte, saber o que realmente importa aos participantes. Na visão de Atkinson (2018), os professores devem ficar atentos às diferentes linhas de aprendizagem dos estudantes. Para isso, é necessário evitar pedagogias prescritivas que buscam a transcendência dos eventos de aprendizagem e "[...] restaurar o trabalho pedagógico à incipiência e imanência da aprendizagem" 


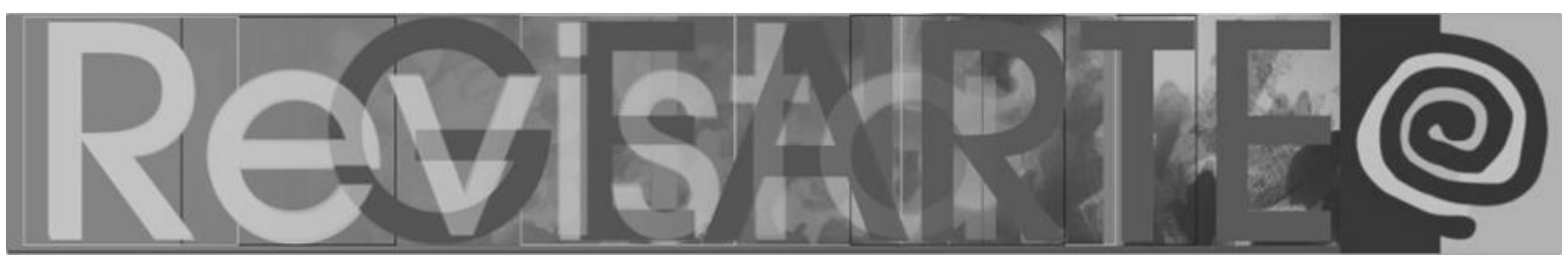

(ATKINSON, 2018, p. 20). Como professores, carregamos abordagens teóricas e marcos conceituais que molduram nosso trabalho para obter um maior sucesso dos estudantes no mercado de trabalho. Atkinson aconselha inverter a ordem e partir do que interessa aos estudantes, partir daquilo que é emergente e que marca a construção de uma vida.

Em terceiro lugar, é aconselhável criar aberturas, ou rachaduras, nas estruturas rígidas dos modelos educativos e nas epistemologias que as guiam. No caso da educação em artes visuais, as aberturas são em si mesmas processos estéticos, se consideramos, como Jacques Rancière (2009), que a estética, ou o sensível, é também um ato político que cria rupturas com o estabelecido. Um processo é estético porque se faz sensível ao mundo: visível, audível. Passa a ter uma existência e muda a configuração do consenso.

As aberturas aos eventos de aprendizagem, especialmente no ensino da arte ou mais amplamente, das visualidades, são aberturas à vida dos estudantes, seu contexto, sua situação, suas necessidades, seus desejos e suas lutas. Para conhecer os estudantes, as professoras devem criar condições ou provocar eventos que precipitem a aprendizagem. Isso significa dar condições para que os estudantes possam criar e se criar a si mesmos. E criar, como apontado acima, é um evento de mudança que vai da inexistência à existência.

Atkinson identifica esse momento de mudança como um encontro de aprendizagem. É o momento da experiência corporal, da virada na construção do sujeito, da singularidade do tempo e lugar; o momento que se faz possível imaginar outros mundos, ou pensar de outra forma. Ele observa que o que importa ao aprendiz é fundamental para esse encontro:

[...] como um encontro de aprendizagem importa a um aprendiz e como isto se manifesta diferentemente através da força da arte? Podemos relaxar da transcendência da tradição, ou posto de outra forma, podemos estar eternamente vigilantes ao seu poder de controle? É esta uma forma de desobediência necessária? Eu uso o termo da força da arte, para me referir a uma profunda força particular do evento da arte que precipita potencias ontogênicas para construir uma vida (ATKINSON, 2018, p. 23) 


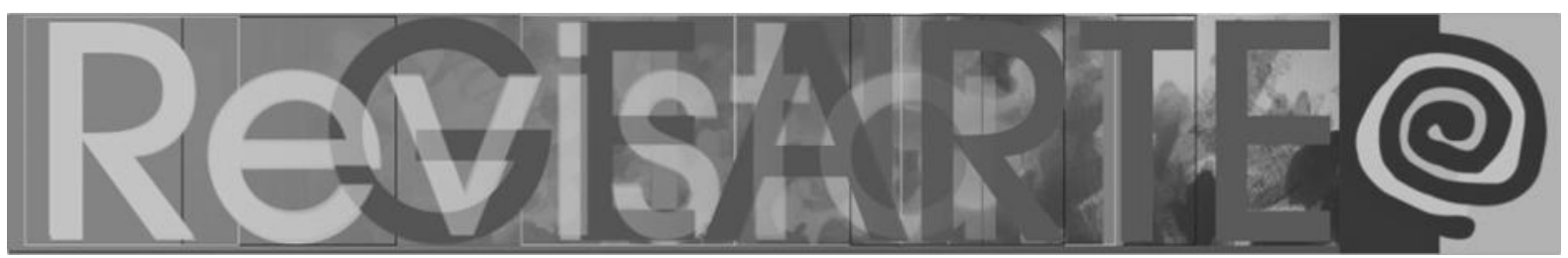

Com essa observação, Atkinson argumenta que não é o pensamento que pensa a arte, mas a arte que força o pensamento. Nessa perspectiva, a arte é uma força não humana pela qual emerge uma subjetividade que ganha poder. Não é o artista que faz a arte, mas a arte que faz o artista. Da mesma maneira, a força da arte precipita encontros de aprendizagem. Ele observa que quando as crianças desenham, pintam ou exercem uma atividade criativa elas se defrontam com decisões frente ao repentinamente possível, ao emergente, ao que é incontrolável ou surpreendente. Nessa situação, elas decidem qual será a seguinte ação se abrindo para caminhos desconhecidos e, nesse processo, à construção de si mesmos. Atkinson se baseia na ética de Spinoza, que declara a impossibilidade de saber do que um corpo ou uma mente é capaz. Nesse sentido, toda experiência estética é uma exploração do mundo e de si mesmo ao mesmo tempo. O laboratório de todo artista é seu próprio corpo. A aprendizagem envolve encontros entre o humano e o não humano.

Essa é uma visão pós-humanista que considera as relações intercambiáveis entre sujeito e objeto, na qual o humano não é mais o único detentor de uma cultura. Aqui, cabe o melhor exemplo dessa distância: não se aprende sobre a árvore, se aprende da árvore; não se aprende sobre a onça; aprende-se da onça; não se aprende sobre o outro, aprende-se do outro. O processo educativo, nesse caso, não se completa com o um planejamento curricular fechado dentro de um campo conhecido e dentro de uma sala com cadeiras e mesas. Um processo educativo pode se parecer mais a uma aventura que parte de um planejamento, mas se embarca em uma busca do desconhecido. Nessas bases, Atkinson (2018) defende a arte na educação como uma via estratégica para responder à situação em que se encontra o mundo, não somente a situação em que se encontra a educação. Essa é a posição de outros filósofos como Felix Guattari (1995) ou Suely Rolnik (2018) sobre a necessidade das micropolíticas e seus alcances. Da mesma forma, diversos teóricos da cultura, arte, educação e política como Gayatri Spivak (2012), Bell Hooks (2017), e artistas teóricos como Irit Rogoff, Anton Vidokle e Pablo Helguera entre outros que trabalham com interfaces pedagógicas, pensam 


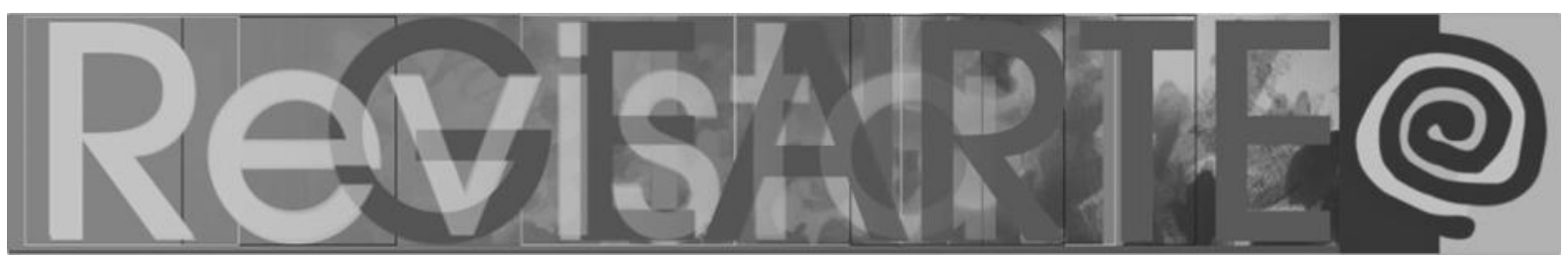

que uma educação ético-estética cria rupturas nas relações de poder necessárias para as mudanças das relações no tecido social.

As aberturas às operações que acontecem na arte permitem manter o foco nos interesses do estudante/participante ao mesmo tempo em que propicia a observação, a reflexão, a crítica e a criação sobre o currículo determinado pela sociedade, ou comunidade no seu projeto político pedagógico. Para fazer aberturas nos processos de ensino, eu me baseio na metodologia IBA de maneira a produzir eventos artísticos, ou "máquinas desterritorializadoras" (GUATTARI, 1995), como eventos pedagógicos. Os eventos artísticos e pedagógicos, entendidos aqui na perspectiva de Badiou e Atkinson, considerando que "[...] a arte é uma força que precipita potências" (ATKINSON, 2018, p. 23). São cinco operações de abertura que uso para provocar eventos artísticos como eventos pedagógicos: a imaginação, a corporificação, a subjetivação, a singularização e a diferenciação. Na educação tradicional, essas operações são fechadas. E não é uma tarefa fácil abri-las. E como pensa Guattari (1995), as operações que são de ruptura e sutura são operações estéticas.

\section{As aberturas}

Um processo de aprendizagem baseado nas formas de operar da arte deve começar por ter abertura às operações da imaginação. A teórica dos Estudos Culturais, Gayatri Spivak (2012), pensa que a educação estética deve treinar a imaginação às performances epistemológicas alternativas. Não somente outras ideias, mas outras formas de pensar. O exercício da imaginação permite maior flexibilidade intelectual e capacidade crítica. Para a educadora Maxine Greene (2000), a imaginação social é uma poderosa forma de transformar a realidade porque permite inventar novos mundos para viver. Toda forma de operar das artes trabalha sobre a imaginação. A imaginação é o espaço do desconhecido, o horizonte que sempre se amplia, o que ainda não existe, mas está em potência. Sem a imaginação, que se manifesta esteticamente, não nos conectamos com o mundo e os mundos. O exercício da imaginação é fundamental para a existência 


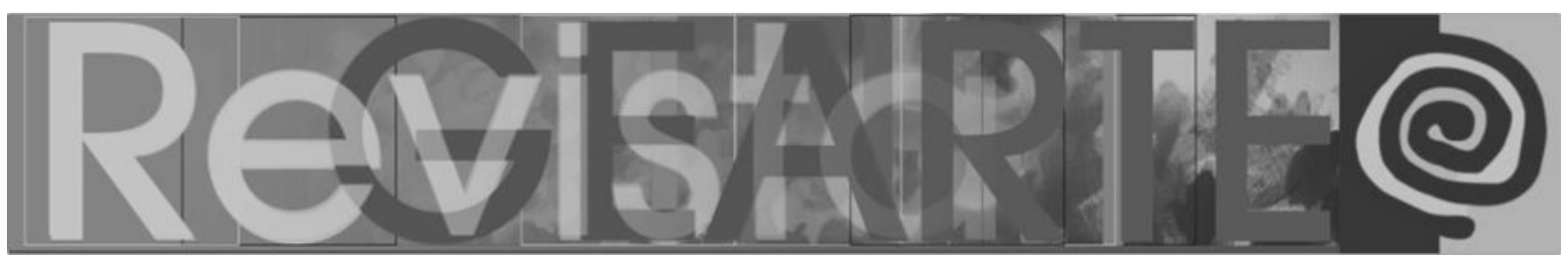

humana. Nos processos de aprendizagem, a realidade e a imaginação se entrelaçam. A memória precisa da imaginação assim como a projeção do que se quer construir. Imaginar conduz às buscas que conectam aprendizagens e que produzem conhecimento valioso para a sociedade.

Por outra parte, as aberturas às operações da corporificação são fundamentais no ensino da arte. Essas operações se dão quando os estudantes se envolvem em processos criativos, nos quais se trabalha com os sentidos e todo o corpo, geralmente restrito ao Ensino Fundamental. Na educação secundária, prefere-se abordagens teóricas para estudar objetos de avaliação de provas externas. Mas a abordagem geralmente é o da arte como disciplina que tem certos conhecimentos específicos, como os históricos ou os semióticos, que devem se aprender de forma tradicional, isto é, no modelo científico em que é predominante a palavra. Mas, mesmo os conhecimentos teóricos podem se aprender de forma criativa, artística, estética e poética, isto é, usando operações de abertura ao sensível. Aprender por meio da experiência corporal é também uma forma de usar operação artísticas. Por outra parte, a aprendizagem corporificada é uma educação empoderadora, que promove não só maior entendimento do mundo, mas de si mesmo como fonte de poder e de transformação.

Já as aberturas a operações de subjetivação são aquelas que permitem que os sujeitos participantes do evento artístico-pedagógico se apropriem do processo de aprendizagem ou do processo artístico e controlem com ele sua própria arquitetura do self, construam-se a si mesmos a partir da sua relação com o campo de estudo. Por isso, os processos pedagógicos precisam incluir os interesses dos estudantes, mas também conhecer o contexto. São aberturas para que os sujeitos participantes se encontrem na aprendizagem, para que o que aprendam contribua à imagem que tem de si mesmos. Geralmente, esse aspecto é ignorado na escola, onde importa mais uma informação para passar uma prova em um futuro incerto do que uma aprendizagem para construção de uma vida real, atual e singular. 


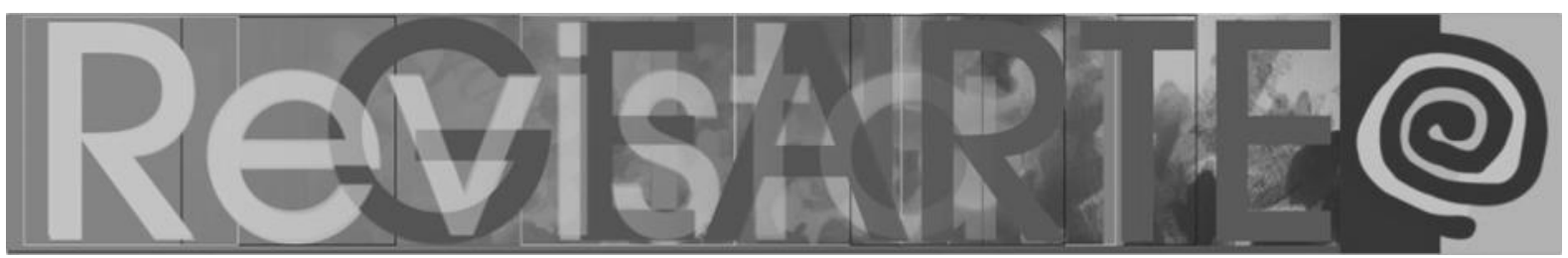

Atkinson (2018) e outros teóricos da educação, como Paulo Freire (1987), Giroux (2005) ou Gert Biesta (2010, 2012), advertem que uma educação cujo propósito é homogeneizar os saberes e conhecimentos, no modelo de uma educação bancária, tem por objetivo manter a relações de poder entre opressores e oprimidos. Embora muitos professores tenham consciência disso, não conseguem escapar da memorização de conteúdo, das provas de múltipla escolha, do binarismo do certo-errado, da cultura do rendimento. Por isso, é necessário criar aberturas para operações de singularização. Isso significa desenhar atividades de aprendizagem cujos resultados devem ser por força da proposta, singulares. Evidentemente as operações de singularização em salas de aula lotadas e com muitas turmas e muitos turnos na semana se torna um grande trabalho para professores. Mas é também evidente que um processo artístico não pode ser idêntico a outro. As operações de singularização, que não são de individualização, favorecem tratamentos singulares, experiências únicas do mesmo problema e requerem a disposição de recursos em sala de aula. As operações de singularização, por outro lado, não se medem pela originalidade das criações ou ações artísticas, mas pela relevância das diferenças que fazem diferença.

Por isso, é importante ter aberturas às operações de diferenciação, pois sem elas a abertura às operações de singularização e de subjetivação estariam incompletas ou impedidas. O contraditório, o diferente ou dissidente dificilmente encontra passo na escola tradicional. As operações de diferenciação asseguram espaço para ter outras ideias ou pensar de outra forma. Nos processos de aprendizagem, é fundamental tomar em conta os interesses dos estudantes, mas eles somente aparecem quando existe espaço para se posicionar frente ao que se aprende. Os estudantes aprendem mais fora da escola do que dentro. E aquilo que sabem pode estar em contradição com o que se ensina na escola. As aberturas às operações de diferença e dissidência devem fazer parte de processos artísticopedagógicos que se baseiam na ideia de emancipação do espectador ou do estudante (RANCIÈRE, 2011) que é, em todo caso, o participante. Essas aberturas são complexas porque devem permitir e enfrentar o pensamento divergente e 


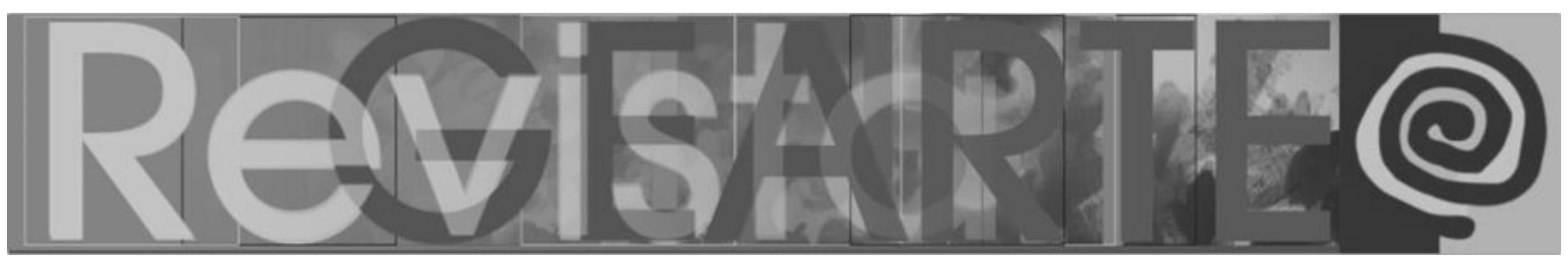

trabalhar sobre o dissenso. Nessas operações, deve se manejar conflitos e não os ignorar.

Essa abertura é muito controversa porque ensina a transgredir (HOOKS, 2017). O educador em cultura visual Paul Duncum (2009) observa como os professores de arte abordam a transgressão no ensino da arte baseado nas três categorias de transgressão artística (JULIUS, 2003): a que rompe com suas próprias regras; a que rompe com os sentimentos, crenças e tabus da audiência e a que rompe com regras políticas. Ele observa que os professores somente mostram as categorias 1 e 3, mas os estudantes caem na categoria 2. É importante lembrar que é muito comum não permitir nenhuma das categorias de transgressão na escola. Mostrar arte transgressora é o máximo de transgressão que se permite. Por esse motivo, são aberturas que devem ser pensadas como eventos artísticos.

\section{A marca das aberturas}

A possibilidade de processos de aprendizagem com aberturas às formas de operar das artes responde tanto às necessidades de aprendizagem identificadas pelos projetos curriculares institucionais como às formas em que aprendem os estudantes ao mesmo tempo em que conecta essas potencias ao currículo. No caso do Brasil, isso significa considerar as capacidades necessárias para que os estudantes possam passar em provas e vestibulares. A habilidade pedagógica consiste, então, em articular os conhecimentos e saberes gerais com os interesses particulares dos estudantes. No ensino das artes visuais, essa articulação é complexa porque geralmente a arte, como produto de um sistema de arte, é distante da vida dos estudantes e, na forma em que é ensinada, não afeta sua vida de forma direta. No entanto, o princípio pode ser simples: criar aberturas nos processos de aprendizagem à imaginação, à singularização, à corporificação, à subjetivação e à diferenciação.

Nos Estágios Supervisionados em Artes Visuais na Universidade de Brasília, observo que, de maneira geral, há ceticismo de abordagens abertas ao 


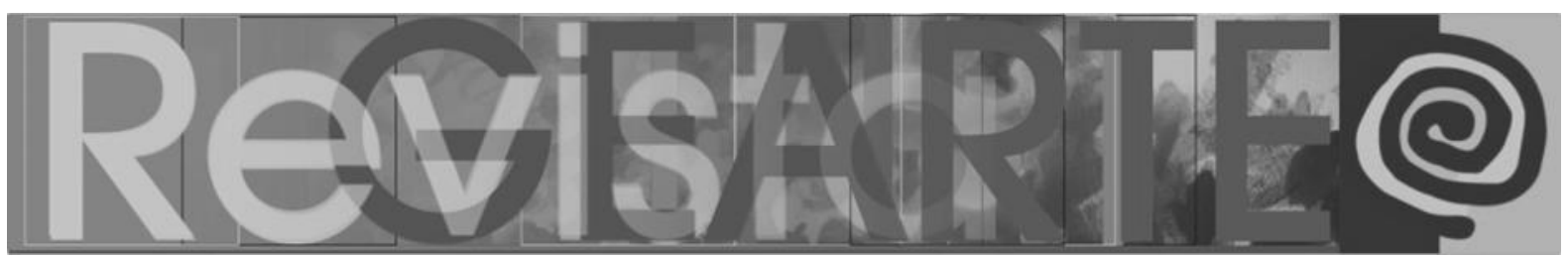

que importa ao estudante, no Ensino Médio, especialmente, porque há um compromisso com a preparação dos estudantes para passar nas provas externas e professores e estudantes devem se concentrar em estudar os Objetos de Avaliação do Programa de Avaliação Seriada (PAS-UnB/CEBRASPE) do vestibular e do Exame Nacional do Ensino Médio (ENEM). Isso não significa que as provas externas para o acesso ao ensino superior não importem aos estudantes do Ensino Médio. Mas parece haver uma contradição entre o discurso acadêmico que prega um ensino centrado no estudante e a realidade das escolas públicas e particulares onde as condições para essas formas de pedagogia são limitadas, com mínimos recursos ou espaços e dentro de comunidades escolares que consideram a arte uma atividade menor, ou que somente faz parte de exigências para passar em vestibulares.

O objetivo do sistema da educação é formar estudantes capazes de ter um papel produtivo na sociedade. Sendo que a produtividade é julgada sobre a ótica capitalista, é, então, necessário homogeneizar o currículo escolar no mundo. Para isso foram criados padrões de qualidade como o Programa Internacional de Avaliação de Estudantes (PISA). Das professoras, exige-se formar pessoas que respondam a esses padrões. Nesses processos, as instituições educativas também são avaliadas. Frente a isso, minhas estudantes de educação em artes visuais nos estágios manifestam sua preocupação quando sentem o abismo entre a teoria, que parece resolver tudo, e a prática, na qual a execução não é possível, dada a quantidade de estudantes e os horários fragmentados que não permitem conhecê-los. Elas se perguntam como aprender, então, das formas em que os estudantes aprendem? Como ensinar considerando a imanência da situação em um sistema que mede as práticas pedagógicas em termos de produtividade com salas lotadas? Como alcançar uma aprendizagem autêntica se estamos sempre em modo controle de danos? Como abordar uma educação em visualidades centrada no estudante?

Não existe outra verdade que aquela que se desprende na emergência dos efeitos e afetos. Se a arte é uma prática desobediente, como pensa Rancière 


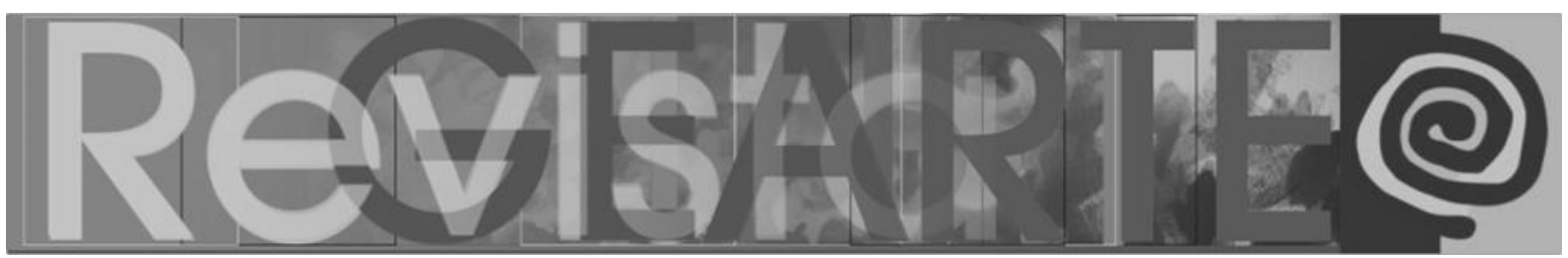

(2009), estamos entrando no espaço da estética. Como professores de arte, trabalhamos nas fronteiras do compreensível. Prefiro pensar como Stephen Wright (2006), que diz que o artista é um espião com uma agenda artística secreta e a arte como uma interferência na realidade. $O$ importante, então, é criar eventos que produzam rachaduras estéticas nas quais os participantes possam tomar para si a aprendizagem. Estudar os Objetos de Avaliação de provas externas não é um impedimento para a sua exploração por meio de aberturas nos processos. Os obstáculos são outros. Geralmente, estão na pouca valoração da comunidade educativa, como um todo, dos processos artísticos para a construção do conhecimento.

Essa preocupação, aumentada nos anos de pandemia e das crises políticas e econômicas do século XXI, é legítima, embora parte do princípio de que uma pedagogia aberta ao que realmente interessa ao estudante é incompatível com um projeto educativo nacional, regional ou comunitário e menos ainda, com provas vestibulares massivas. A pergunta então se torna: como unir conhecimentos básicos aos interesses e condições tão diversas? Será possível provocar eventos artístico-pedagógicos que levem os estudantes a criar e se autocriar ao mesmo tempo em que se tornam competentes para passar nas provas para a entrada no ensino superior? As formas de operar das artes, que a metodologia de IBA nos leva a observar na construção de conhecimento, têm o potencial de contribuir nessa tarefa.

A arte tem operações para articular o particular com o universal, para encarnar o outro, para se tornar outro. Por outro lado, as práticas artísticas podem constituir por si mesmas formas de aprender e apresentam aberturas às operações que conectam conhecimentos com interesses diversos. As práticas artísticas operam também dentro das tradições empiristas, interpretativas e críticas das ciências (SULLIVAN, 2010) além de serem criativas. Essas práticas exploram os campos disciplinar, interdisciplinar e transdisciplinar como a ciência, mas também o campo pós-disciplinar, já que se abordam saberes não disciplinados. Essa capacidade de transição das práticas artísticas permite construir conhecimentos 


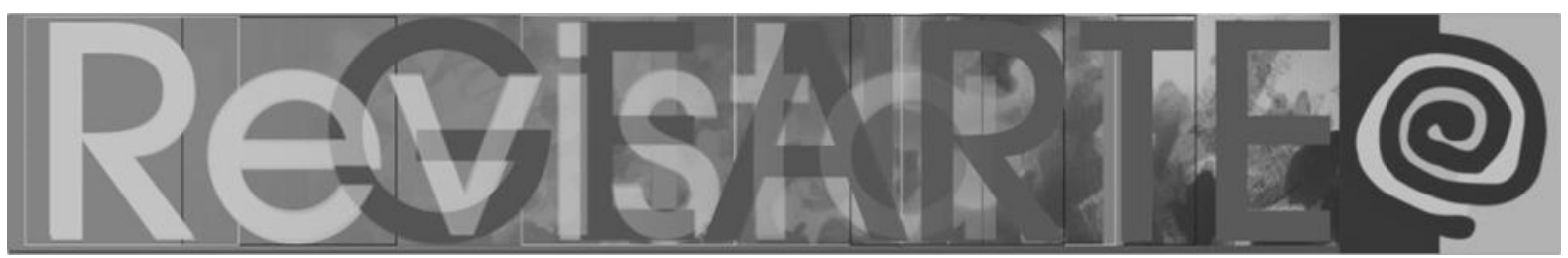

sólidos e coerentes e, inclusive, contribui na conexão de diversas aprendizagens em diferentes áreas com praticamente qualquer tema ou situação.

Porque, na contingencia do cotidiano, na tormenta de emoções que nos atravessam na escola pelo fato de estar juntos e aprender juntos, não há como se aferrar a um planejamento estrito ou a um currículo impermeável aos acontecimentos. Atkinson se pergunta se não podemos baixar a guarda à transcendência do currículo escolar. Outros teóricos como William Pinar e Rita Irwin (2005) pensam em termos de um currículo vivo que se entrelaça na vida dos estudantes e que se faz, além do mais, como um currere antes que como currículo, isto é, que se constrói no processo vivido. O currículo vivo é também uma forma de pensar a co-autoria entre o professor e o estudante de um percurso educativo para responder às necessidades reais dos estudantes e dos seus contextos comunitários. No entanto, o que observo nas supervisões dos Estágios Supervisionados é que a grande dificuldade de professoras e estagiárias não é partir das experiências vivas, das necessidades dos estudantes ou do cotidiano. Ao contrário, todas manifestam a necessidade de integrar a vivência dos estudantes e saberiam fazer isso, mas se sentem forçadas a uma abordagem fechada pela preocupação com a preparação para a entrada no ensino superior. E, nos casos em que não há essa preocupação (Educação de Jovens e Adultos, Educação do Campo), a arte tem uma abordagem tecnicista e artesanal.

$\mathrm{Na}$ formação de professoras de arte é necessário observar que, sendo a arte um campo crítico todo espaço de manifestação expressiva, ela tem potencial de conexão com os interesses juvenis. Isso inclui o uso da tecnologia que é produtora de cultura visual. Os jovens são criadores de visualidades e a sala de aula precisa ser um espaço de pesquisa para explorar em relação ao que já se sabe e imaginar o que pode chegar a ser. É conveniente pensar a sala de aula de arte como um laboratório de exploração estética do mundo em que o currículo potencie e amplie as pesquisas singulares que se alimentam na comunidade. Por isso, é fundamental conhecer os objetivos políticos determinados pela da escola, 


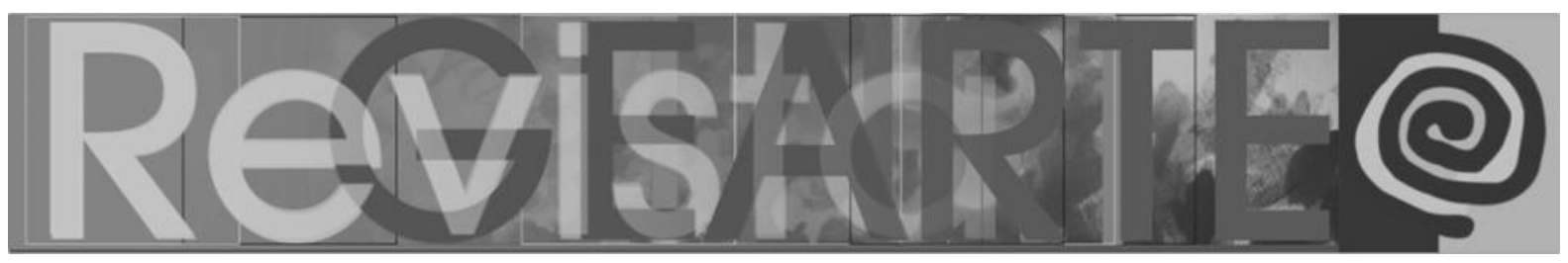

a legislação regional ou nacional e ao mesmo tempo se manter aberto à imanência dos eventos que nos tomam no contexto escolar e na vida.

Evidentemente, saber arquitetar os eventos, entender as preocupações, captar os sinais, articular os processos do que é necessário aprender (para o objetivo político) com os interesses reais dos estudantes (para os objetivos de vida dos sujeitos que aprendem) requer dos estudantes das licenciaturas de educação em artes visuais não somente saber aprender, mas saber desaprender, se autossabotar (FERNÁNDEZ, 2018), inverter os papéis, pensar de outras formas. O artista Pablo Helguera, criador da Panamerican School of Unrest (2003-2006), aprende dos seus participantes, invertendo os papéis de estudante-professor, para iniciar processos que são pedagógicos e artísticos. É necessário que a professora de arte perca o controle dos resultados, que deixe as visualidades invadirem o imaginário dos cantos escolares, que fure o muro da escola com aberturas para que fluam por ali as incertezas da vida, as formas monstruosas que não queremos ver como sociedade. Para Atkinson, essa é uma pedagogia da desobediência (2018), uma pedagogia contra o estado (2011), em que a professora de arte reconhece o valor ético-estético dos eventos que nos afetam e navega nas águas intensas do aqui e agora.

Arte não é um instrumento para aprender, é uma força desterritorializadora para desaprender, pois abre novas formas de ver. Isso pode ser muito vago em termos de resultados de aprendizagem para as avaliações de padrões de qualidade educativa. Pode ser pouco possível mensurar a forma como, professores de arte afetamos a vida dos nossos estudantes. Os indícios podem ser quase invisíveis e se manifestarem ao longo dos anos em outras formas de operar mais artísticas e abertas. Pesquisas como as do Project Zero da Faculdade de Educação da Universidade de Harvard (GARDNER, 2011), que levam anos investigando a forma como a prática da arte afeta a subjetivação e a cognição, mostram que as mudanças se dão com as práticas contínuas da arte ao longo da infância e juventude, em que a prática é esporádica e superficial e não há mudanças. O que sabemos é que a capacidade criadora ativa processos cognitivos 


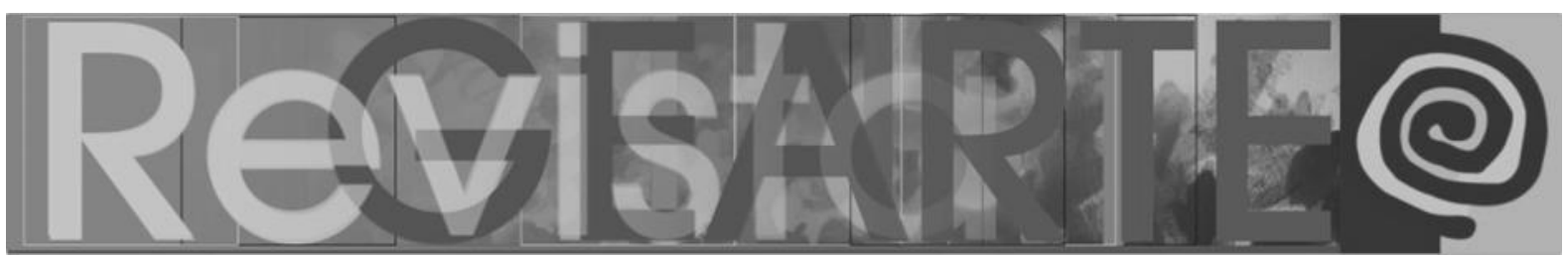

e biológicos importantes para a saúde e a inteligência. A criação é sempre um exercício de construção e desconstrução do mundo e de si mesmo. Mas tudo isso não impede medir resultados de aprendizagem a partir do que podemos valorizar (avaliar) nos processos de subjetivação, singularização, corporificação, imaginação e diferenciação, além daqueles que dizem respeito ao currículo e às avaliações externas.

Se separamos o currículo do interesse de vida dos sujeitos em processo de educação há um desencontro cognitivo e biológico. A forma de promover esse encontro é marcar linhas de fuga, criar rachaduras por onde os estudantes possam interferir sobre a arquitetura de si mesmos, onde devam tomar decisões por si mesmos e criar, onde possam se posicionar e atuar, onde possam dissentir e onde possam sentir e se sentir. A experiência estética é, aqui, elo entre a emancipação e a capacitação para um mundo que exige competências e habilidades específicas para um mercado. Hoje, ser criativo constitui uma exigência laboral no mercado de trabalho junto ao conhecimento de tecnologias. Precisa-se de pessoas criativas que respondam de forma inventiva e autônoma às situações de crise ou para criar uma diferença qualitativa nos produtos. As competências que se exigem se dirigem a um mundo cada vez mais tecnológico, autônomo, consumista e criativo.

\section{As rupturas das linhas de aprendizagem}

Para alguns a criatividade é uma inovação que representa uma plus-valia para o sucesso nos negócios. Para outros, a criatividade é a desobediência de maneira que não pode estar condicionada a uma exigência externa ao evento criativo. Para outros, é uma forma de investigar o mundo. E para outros, ainda, a criatividade é uma capacidade que responde a necessidades concretas. O que temos em comum é que somos seres criadores e que nossa capacidade criadora é a que nos proporciona poderes para sobreviver e construir novos mundos. Hoje, como nunca e como sempre temos que nos recriar. Podemos começar com uma marca, uma linha de fuga, uma rachadura, uma ruptura. Uma linha para se 


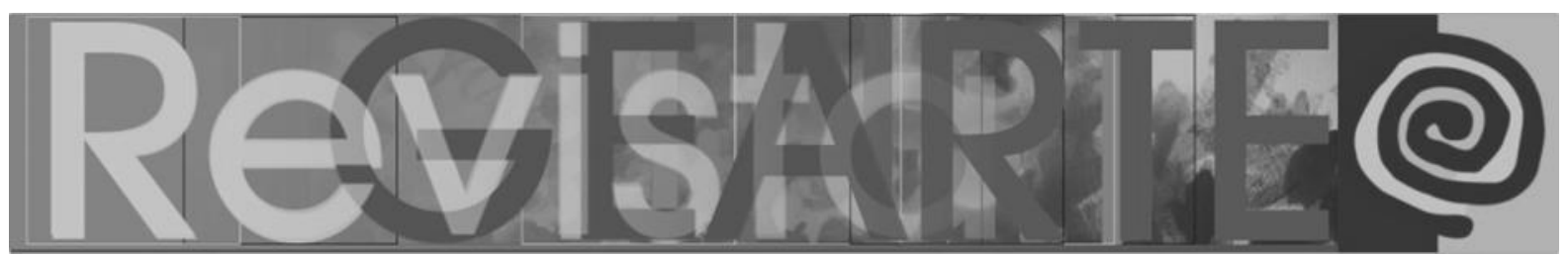

desenhar a si mesmo nos eventos artísticos e pedagógicos que nos atravessam. Essas seriam as linhas de aprendizagem a que Atkinson se refere (2018).

A linha no rosto, às vezes reta, às vezes ponteada, às vezes torta, às vezes branca, às vezes preta, marca duas décadas de eventos pedagógicos como eventos artísticos na singularidade da minha vida. Trata-se de uma operação estética, porque marca três rupturas com linhas de aprendizagem na minha vida: uma é com aquilo que Freire chama de educação bancária, que reproduz a divisão do mundo entre opressores e oprimidos, entre mente e corpo, entre sujeito e objeto ou entre bem e mal. A outra é uma ruptura com o policiamento do sistema da arte que rege aquilo que deve ser visto como arte daquilo que não deve ser considerado, assim: o evento pedagógico, como evento artístico, foge ao radar daquilo que é visível como arte para as instituições da arte. Se diferencia das ações que levam projetos artísticos na escola, onde importa mais o prestígio do artista do que $o$ interesse dos estudantes. Isso acontece nos lugares em que o coeficiente de visibilidade de um evento participante se centra somente no artista. A terceira ruptura é com a ideia de uma criatividade que é dada por um sistema exterior aos sujeitos e um commodity para o capitalismo. Uma professora de arte não ensina criatividade, abre rachaduras nos eventos pedagógicos em que a criação começa pela marca da existência para dar passo a novas linhas de aprendizagem.

Em uma pedagogia do evento em que toda diferença faz diferença, as linhas de aprendizagem dos participantes transformam a linearidade ou circularidade das formas de construir conhecimento em linhas desordenadas que produzem encontros de aprendizagem surpreendentes, inusitados, portadoras de outras formas de ver o mundo e de ser visto pelo mundo. Nesse caso, os eventos pedagógicos que operam como eventos artísticos por meio das suas aberturas chamam a uma forma de emancipação e empoderamento pela experiência mesma da arte. Não se aprende sobre a arte, aprende-se da força inumana da arte que move o poder da criação e da autocriação. 


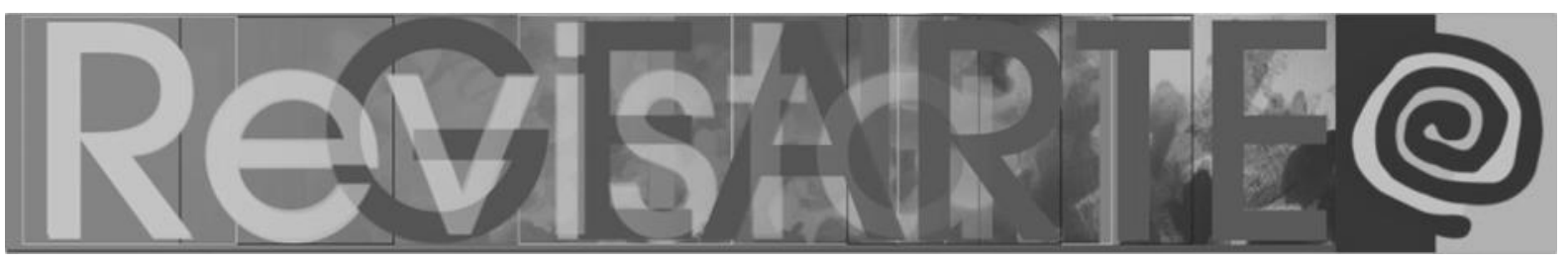

\section{Referências}

ATKINSON, Dennis. Art, Equality and Learning: Pedagogies against the State. Rotterdam: Sense Publishers, 2011.

ATKINSON, Dennis. Art, Disobedience and Ethics: the adventure of pedagogy. London: Palgrave Macmillan, 2018.

BADIOU, Alain. Being and Event. New York: Continuum 2005.

BARONE, Tom; EISNER, Elliot. Arts Based Research. LA: SAGE, 2012.

BIESTA, Gert. A New Logic of Emancipation: the methodology of Jacques Rancière. Educational Theory. vol. 60, n 1, p. 39-59, 2010.

BIESTA, Gert. Science or Democracy Knowledge: Evaluation and Judgment in the Knowledge Society. UK: University of Stirling, 2012. Disponível em: <http://static.sdu.dk/mediafiles//images/ om_sdu/faellesadministrationen/sdue/gert\%20biesta.pdf>. Acesso em: 15 jul. 2012.

DEWEY, John. Arte como Experiência. São Paulo: Martins Fontes, 2010.

DIAS, Belidson. Investigação Baseada em Arte em tempo de mudança da Arte Educação. 2016. In: VENTURELLI, Suzete; ROCHA, Cleomar (org.) Mutações, confluências e experimentações na Arte e Tecnologia. 1ed Brasília: Editora PPG/ARTE UNB, p. 7-24, 2016.

DUNCUM, Paul. Toward a Playful Pedagogy. Popular Culture and the Pleasures of Transgression. Studies in Art Education. vol 50, n 3, p. 232-244, 2009.

FERNÁNDEZ, Tatiana. O evento artístico como pedagogia. Tese doutoral. Programa PósGraduação em Artes Visuais, Departamento de Artes Visuais, Instituto de Artes, Universidade de Brasília, p. 321, 2015.

FERNÁNDEZ, Tatiana. Criatividade, Poética e autosabotagem na educação em visualidades. In: MIRANDA, Fernando; VICCI, Gonzalo; ARDANCHE, Melissa (org.) Dispositivos y Artefactos, Narrativas y Mediaciones. Actas del I Seminario Internacional en Arte y Cultura Visual. Universidad de la República, Montevideo Uruguay, p. 608 -6012, 2018.

FREIRE, Paulo. Pedagogia do Oprimido. Rio de Janeiro: Paz e Terra, 1987. 17 ed.

GARDNER, Howard. Frames of Mind: The theory of multiple intelligences. New York: Basic Books, 2011.

GIROUX, Henry. Border Crossings: Cultural Workers and the Politics of Education. New York: Routledge, 2005.

GREENE, Maxine. Releasing the Imagination: Essays on Education, the Arts, and Social Change. San Francisco: Yossey-Bass, 2000.

GUATTARI, Felix. Chaosmosis: an ethico-aesthetic paradigm. Indianapolis: Indiana University Press, 1995.

HOOKS, bell. Ensinando a transgredir: a educação como prática da liberdade. São Paulo: WMF Martins Fontes, 2017.

JULIUS, Anthony. Transgressions: the offences of art. Chicago: University of Chicago, 2003.

RANCIÈRE, Jacques. A Partilha do Sensível. São Paulo: Editora 34, 2009.

RANCIÈRE, Jacques. The Emancipated Spectator. London: Verso, 2011.

ROLNIK, Suely. Esferas da Insurreição: notas para uma vida não cafetinada. N-1 Edições, 2018.

PINAR, William; IRWIN, Rita. Curriculum in a New Key: The Collected Works of Ted. T. Aoki. London: Lawrence Erlbaum Associates, 2005. 


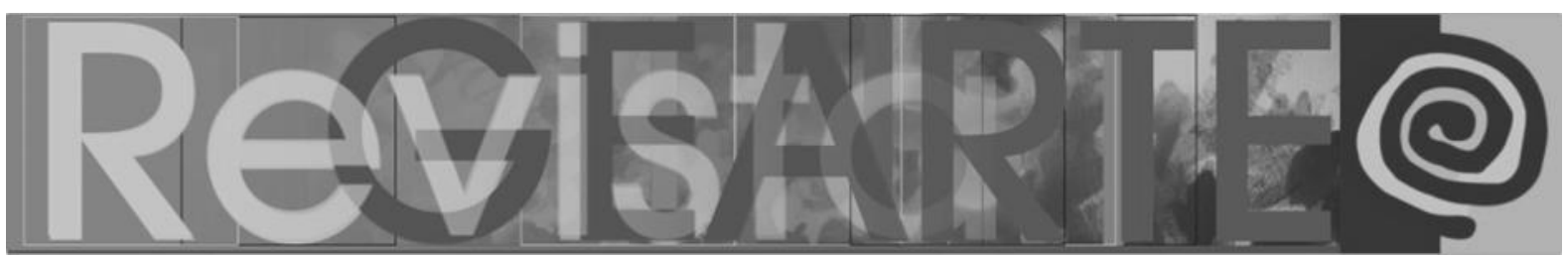

SPIVAK, Gayatri. An Aesthetic Education in the Era of Globalization. Cambridge: Harvard University Press, 2012.

SULLIVAN, Graeme. Art Practice as Research: Inquiry in Visual Arts. LA: SAGE Publications, 2010.

WRIGHT, Stephen. Spy Art: Infiltrating the Real, Afterimage, n³4, vol. 1-2, p. 52-55, 2006.

WRIGHT, Stephen. Behind Police lines: Art Visible and Invisible. Art And Research: A Journal of Ideas, Contexts and methods. Vol. 2, $\mathrm{n}^{\circ}$ 1, Summer, 2008. Disponível em: <http://www.artan dresearch.org.uk/v2n1/wright.html > Acesso em: 27 fev. 2021.

\section{Tatiana Fernández}

Professora Adjunta nível 3 do Departamento de Artes Visuais do Instituto de Artes da Universidade de Brasília. Doutora em Arte pela mesma Universidade. Sua pesquisa é sobre eventos artísticos como pedagogias culturais, estética e política, estéticas decoloniais, políticas de identidade, a virada pedagógica na arte e a virada da visualidade na educação, Objetos de Aprendizagem e tecnologias na educação em visualidades.

ORCID: https://orcid.org/0000-0002-7638-4448

E-mail: tatiana.fernandez@unb.br

Currículo: http://lattes.cnpq.br/2809713635725046

Recebido em 2 de junho de 2021 Aceito em 26 de outubro de 2021 